\title{
Genotyping live fish larvae: Non-lethal and noninvasive DNA isolation from 3-5 day old hatchlings
}

\author{
G. Janelle Espinoza ${ }^{1, *}$, J. Michael Poland ${ }^{1}$, and Jaime R. Alvarado Bremer, 2,* \\ ${ }^{1}$ Department of Marine Biology, Texas A\&M University, Galveston Campus, Galveston, TX and ${ }^{2}$ Department \\ of Wildlife and Fisheries Sciences, Texas A\&M University, College Station, TX
}

${ }^{*}$ G.J.E. and J.R.A.B. contributed equally to this work.

BioTechniques 63:181-186 (October 2017) doi 10.2144/000114598

Keywords: eDNA; DNA isolation; non-invasive; non-lethal; live fish larvae; genotyping

Supplementary material for this article is available at www.BioTechniques.com/article/114598.

Genotyping fish larvae is a valuable technique for numerous fields of study. While methods for collecting DNA from early stage larvae have been published, a non-lethal, non-invasive genotyping protocol for hatchlings that is amenable to high-throughput approaches is desirable. Here, we describe a method to individually genotype live, free-swimming, early fish larvae by characterizing their environmental DNA (eDNA). We demonstrate the utility of the method by assigning parentage to a sample $(n=50)$ of 3-5-day-old sheepshead minnow (Cyprinodon variegatus) larvae hatchlings, with very high rates of genotyping success (98\%) and survival (92\%) using mitochondrial and microsatellite DNA data. This method could be easily adapted to characterize early fish larvae from other model and non-model fish species, such as Danio rerio (zebrafish) and Medaka medaka.

The ability to genotype fish larvae is leading to important advances in several fields, including aquatic toxicology (1-4), global climate change (5), population genetics $(6,7)$, aquaculture $(8,9)$, and developmental and biomedical genetics $(10,11)$. The small size of fish larvae limits tissue availability; thus, when live specimens are not required, DNA yields are maximized by digesting dissected body parts (e.g., eye balls or caudal peduncles) or entire specimens (References 5, 12, 13, and especially Reference 14). By contrast, non-lethal tissue sampling is required when the genotyped larva is to be followed through ontogeny. While non-lethal protocols based on skin swabs and fin clips have been developed $(15,16)$, their universal adoption has been curtailed by two main shortcomings. First, dissecting small fin biopsies (12) from very small specimens (i.e., zebrafish embryos) is labor-intensive and requires highly technical skills and equipment. Second, minimally invasive sampling methodologies amenable to high-throughput approaches $(14,15)$ have only been shown to be effective on fishes older than 71 days post-fertilization (dpf), as handling of the younger, more delicate specimens is often lethal. Accordingly, a non-lethal and non-invasive genotyping protocol that can be used to genotype large numbers of live early fish larvae is still needed.

Here, we describe a noninvasive genotyping method for live fish larvae based on the collection of aqueous environmental DNA (eDNA). We demonstrate the utility of this approach by genotyping 3-5 day post hatch (dph) sheepshead minnow (Cyprinodon variegatus) larvae $<6 \mathrm{~mm}$ in total length (TL) at two mitochondrial DNA (mtDNA) loci and at two nuclear DNA (nDNA) loci with a low mortality rate and with sufficient resolution to unequivocally assign parentage.
Materials and methods

Capture, housing, and breeding

The sheepshead minnow was chosen because it displays sexual dimorphism, is easy to breed, and has a short life cycle. In addition, it is a model species frequently used in ecotoxicology due to its hardiness, euryhaline physiology, and its capacity to withstand low and high dissolved oxygen (DO) concentrations (www.epa.gov/sites/ production/files/2015-09/documents/ sheepsheadminnow.pdf) $(17,18)$. This study complied with State of Texas regulations regarding the capture of non-game fish enforced by Texas Parks and Wildlife Department, and with U.S. Federal policies on the use of laboratory animals as subjects (AUP\# 2014-0043). Sheepshead minnow adults were captured in Galveston Bay, Texas, using minnow traps baited with cat food kibble.

Specimens were sorted by gender and assigned to separate 40-gallon tanks

\section{METHOD SUMMARY}

We describe a novel approach for genotyping live fish hatchlings that has both a high degree of success and a high rate of survival. The key improvements offered by our method are (i) the ability to capture environmental DNA (eDNA) from the water where an individual larva is held using (ii) a commercially available kit. 
containing seawater diluted to 20 parts per thousand (ppt) at $24^{\circ} \mathrm{C}$, and they were acclimatized for a minimum of 2 weeks with a photoperiod of 12L:12D (www.epa.gov/ sites/production/files/2015-08/documents/ short-term-chronic-marine-and-estuarinewet-manual_2002.pdf). After examination for sexual maturity and good health (17), six females and two males were assigned to two broodstocks, namely Broodstock 1 and Broodstock 2, each consisting of three females and one male (three dams and one sire). Broodstocks were housed in 10-gallon aquariums containing 20 ppt seawater maintained at $24^{\circ} \mathrm{C}$ with a photoperiod of 16L:8D (www.epa.gov/sites/ production/files/2015-08/documents/shortterm-chronic-marine-and-estuarine-wetmanual_2002.pdf) and biological filtration and aeration provided by a Penguin Bio-Wheel 100 filter (Spectrum Brands, Blasksburg, VA). Before spawning began, Female 3 died and was not replaced, reducing the number of potential dams in Broodstock 1 to two individuals, and to five for the entire experiment. Yarn mops, used as spawning substrate (19), were inspected daily for eggs, and when present, these were collected by hand and transferred into 1000-mL glass beakers filled with seawater with the same environmental conditions as the broodstock tanks to minimize stress to the developing embryos. Eggs were incubated at room temperature with $24 \mathrm{~h}$ of light to accelerate growth (20).

\section{Isolation of DNA from live larvae}

In total, 50 live larvae (3-5 dph) 4-5 mm TL were tested; 40 from Broodstock 1 and 10 from Broodstock 2. Each larva was transferred into a 1.5-mL microcentrifuge tube (Eppendorf, Hamburg, Germany) containing $200 \mu \mathrm{L}$ sterile 20 ppt Instant Ocean artificial seawater (Spectrum Brands, Blacksburg, VA), using a new 3.0-mL disposable plastic transfer pipette with the tip cut by a sterile scalpel to produce a wide-mouth pipette (20). This first bath minimizes potential cross-contamination with cells from other fish (14). Each larva was then transferred into a second pre-labeled sterile 1.5 -mL microcentrifuge tube filled with $200 \mu \mathrm{L}$ sterile 20 ppt artificial seawater for incubation (see Figure 1 inset) using a new pre-cut disposable wide-mouth pipette. Since it was reasoned that incubation time in the second bath could affect the amount of eDNA released, the entire larval sample was divided into 5 equally-sized sets of

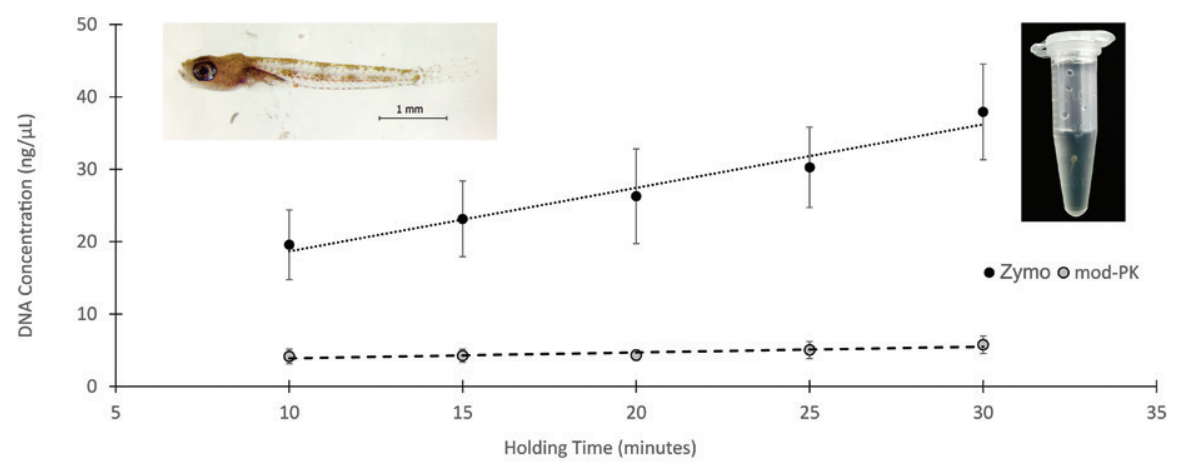

Figure 1. Isolated DNA concentration as a function of live fish larva holding time. Mean DNA amounts (ng/ul) and SEM (vertical bars) are shown for isolations using the Zymo Quick-DNA Universal Kit (Zymo Kit) (filled circles) and the modified proteinase K-EtOH (mod-PK) protocol (empty circles).

10 individuals. Accordingly, 40 larvae from Broodstock 1, the potential offspring of Female 1 and Female 2, were randomly assigned into 4 sets, with members of the first, second, third and fourth group incubated for 10, 15, 20, and $25 \mathrm{~min}$, respectively. Similarly, the 10 larvae from Broodstock 2, the potential offspring of Female 4, Female 5, and Female 6, were held individually for $30 \mathrm{~min}$. Once the holding period ended, each larva was returned to its original $1000-\mathrm{mL}$ beaker to evaluate post-trial survival.

Preliminary attempts to capture aqueous DNA from the $200 \mu \mathrm{L}$ of seawater that held the live larvae were conducted using a modified shake and stew DNA isolation method (14), omitting the shaking step. PCR experiments targeting two mitochondrial DNA (mtDNA) segments, namely the cytochrome c oxidase subunit I gene $(\mathrm{CO} /)$ and control region I (CR-I), using the fish universal primers and conditions as described in References 21 and 22, respectively, resulted in a very low amplification success rate of $20 \%$ for $\mathrm{COI}$ and failed for CR-I. In light of these results, two additional methods of DNA isolation were tested, namely, the Zymo Quick-DNA Universal Kit (Zymo Research, Irvine, CA) and the proteinase $\mathrm{K}$-EtOH precipitation protocol without organic extractions (23), both modified as described below. Amplification of CR-I using the eDNA captured with both methods as template was highly successful (>80\%). Accordingly, these two methods were tested in ensuing experiments, and in order to compare them directly, the entire volume (200 $\mu$ l) of each larva's second bath, which was expected to contain eDNA, was divided into two $100-\mu$ l aliquots. The total volume of the first aliquot was used in lieu of the sterile water employed in the initial step of the Zymo Quick-DNA Universal
Kit (hereafter referred to as the Zymo Kit), reducing the amount of proteinase $\mathrm{K}$ (20 $\mathrm{mg} / \mathrm{mL}$ ) to $5 \mu \mathrm{L}$, with the remaining steps performed according to the manufacturer's instructions. DNA was eluted from the spin column using $100 \mu \mathrm{l}$ warm $\left(65^{\circ} \mathrm{C}\right)$ DNA Elution Buffer from the Zymo Kit. Alternatively, the eDNA present in the second $100-\mu l$ aliquot of seawater was isolated using the modified proteinase $\mathrm{K}-\mathrm{EtOH}$ (mod-PK) protocol where, in anticipation of low DNA concentrations, centrifugation times for precipitation were increased by $50 \%$, and the final elution volume was cut in half. In all instances, the DNA concentration was measured with a NanoDrop 2000 spectrophotometer (Thermo Fisher Scientific, Waltham, MA). DNA isolates were refrigerated at $4^{\circ} \mathrm{C}$ until they were used as PCR templates.

\section{PCR amplification and}

sequencing of mtDNA loci

Two new primer sets based on the mitogenome of $C$. variegatus (Accession number KR061357) were designed to minimize the detrimental effect on PCR of mismatches between primer and template at low DNA concentrations (24). The first set targeted a 355-bp fragment of COI with primers COI-CvarF (5'-ACC AGG CTC TCT TCT GGG C-3') and COI-CvarR (5'-CCG GCA GCA AGA ACA GGA A-3'), selected by the Primer3 software $(25,26)$ as the most optimal pair among potential primer pairs capable of amplifying in silico a fragment 350-400-bp long. The second set targeted 459 bp of the mtDNA Control Region I (CR-I) using primers L15998-CV (5'-GAC CCC TAA CTC CCA AAG CTA-3') and CSBDH-CV (5'-TGA AAT AGG AAC CAG ATG CCA G-3'), which are modified versions of the fish-universal CR-I primer set L15998 and CSBD-H (22) that match 
C. variegatus (i.e., altered nucleotides denoted in bold). PCR was carried out separately for each mtDNA segment in $12.5 \mu \mathrm{L}$ reaction volumes containing: $1 \times$ EconoTaq Plus Green Master Mix (Lucigen, Middleton, WI), plus $2.0 \mu \mathrm{L}$ of isolated DNA as template and $0.1 \mu \mathrm{M}$ of each primer for CR-I amplifications or $1.0 \mu \mathrm{L}$ of isolated DNA and $0.2 \mu \mathrm{M}$ of each primer for $\mathrm{CO}$ amplifications. Thermocycling was performed in an Eppendorf Mastercycler Gradient with an initial denaturing step at $94^{\circ} \mathrm{C}$ for $2 \mathrm{~min}$, followed by 35 cycles of denaturing at $94^{\circ} \mathrm{C}$ for $30 \mathrm{~s}$, annealing at $54^{\circ} \mathrm{C}$ for CR-I or $57^{\circ} \mathrm{C}$ for $\mathrm{CO}$ for 30 $\mathrm{s}$, and extension at $72^{\circ} \mathrm{C}$ for $60 \mathrm{~s}$, with a final extension step at $72^{\circ} \mathrm{C}$ for 10 min. Negative controls were included in all $\mathrm{PCR}$ reactions, and amplicons were visualized in 2\% Tris-acetate (TA) agarose gels pre-stained with ethidium bromide (EtBr). Sequencing of the COI fragment was carried out in both directions using the corresponding forward and reverse PCR primers, with reaction setups and thermocycling profiles as described in Cruscanti et al. (27). COI multiple sequence alignments were conducted in Geneious Pro v.6.1 (Biomatters Ltd., Aukland, NZ) and exported to MEGA v.6.06 (28) where a maximum likelihood (ML) gene tree (29) was constructed with Yucatan pupfish (C. artifrons) (Accession number EU751776) as the outgroup.

\section{PCR amplification and}

characterization of microsatellite loci Multiplex PCR of pupfish-specific (genus Cyprionodon) microsatellite loci AC4 and AC23 (30) was carried out in $12.5-\mu$ reaction volumes containing $1 \times$ EconoTaq Plus Master Mix (Lucigen), $0.1 \mu \mathrm{M}$ of each of the 4 primers, and $3 \mu \mathrm{L}$ of the Zymo Kit DNA isolate as template. Thermocycling consisted of initial denaturing at $94^{\circ} \mathrm{C}$ for $2 \mathrm{~min}$, followed by 35 cycles of denaturing at $94^{\circ} \mathrm{C}$ for $20 \mathrm{~s}$, primer annealing at $53^{\circ} \mathrm{C}$ for $45 \mathrm{~s}$, and extension at $72^{\circ} \mathrm{C}$ for 90 $\mathrm{s}$, with a final extension step at $72^{\circ} \mathrm{C}$ for $3 \mathrm{~min}$. PCR products were diluted $1: 10$, and $1 \mu \mathrm{L}$ of this dilution was combined with $22 \mu \mathrm{L} \mathrm{Hi-Di} \mathrm{formamide}$ and $1 \mu \mathrm{L}$ ROX size standard (both from Thermo Fisher Scientific). Reactions were incubated at $95^{\circ} \mathrm{C}$ for 5 min in an Eppendorf Mastercycler Gradient and run in an ABI 3130 Genetic Analyzer followed by data analysis using
GeneMapper software, v. 4.0 (Applied Biosystems, Foster City, CA).

\section{Characterization of broodstock} and parentage

Fin clips were collected from the members of the broodstock and $\sim 0.5 \mathrm{mg}$ of tissue from each clip was digested to isolate DNA using the proteinase $\mathrm{K}$-EtOH precipitation protocol (23). The COI fragment from each of the five potential mothers was amplified and sequenced in both directions. Since each female displayed a distinct haplotype, it was possible to identify her progeny. COI haplotypes together with the genotypes at two microsatellite loci were used to assign parentage using a genotypic exclusion method whereby parent-offspring genotypes were checked and assigned by eye. Due to the small sample size, results

\section{$A$}

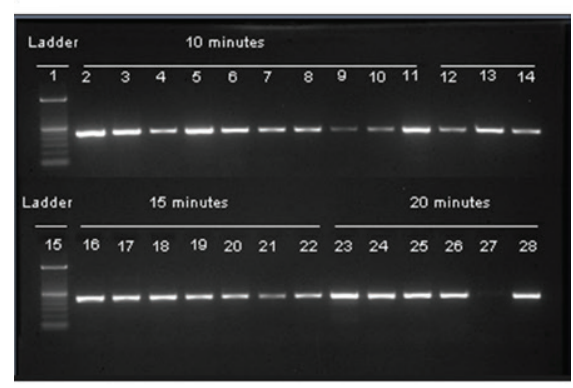

B

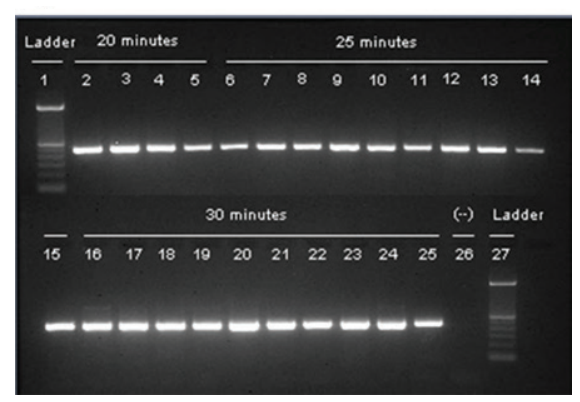

Figure 2. Amplification of a cytochrome c oxidase subunit I gene (COI) segment (335 bp) using eDNA from live sheepshead minnow larvae as template. Template DNA was purified with the Zymo Quick-DNA Universal Kit (Zymo Kit), and PCR products $(5 \mu \mathrm{l})$ were visualized in $2 \%(\mathrm{w} / \mathrm{v})$ Tris-acetate (TA)/agarose/ethidium bromide $(\mathrm{EtBr})$ gels run at $100 \mathrm{~V}$ for $35 \mathrm{~min}$. There were 5 sets of 10 individuals. Larvae in each set were held separately for a predetermined amount of time: (A) $10 \mathrm{~min}$, Lanes 2-11; $15 \mathrm{~min}$, Lanes 12-22; $20 \mathrm{~min}$, Lanes 23-28. (B) 20 min (continued from Panel A), Lanes 2-5; $25 \mathrm{~min}$, Lanes 6-15; $30 \mathrm{~min}$, Lanes 16-25; Lane 26, the negative control $(-)$ for the entire reaction. In both $(A)$ and $(B)$, the "Ladder" lane contained $2 \mu$ of 100-bp DNA size marker (New England Biolabs, Ipswich, MA). The sample for Larva 5 in the 20 min set (Lane 27) failed to amplify in this reaction but was amplified in a subsequent PCR.

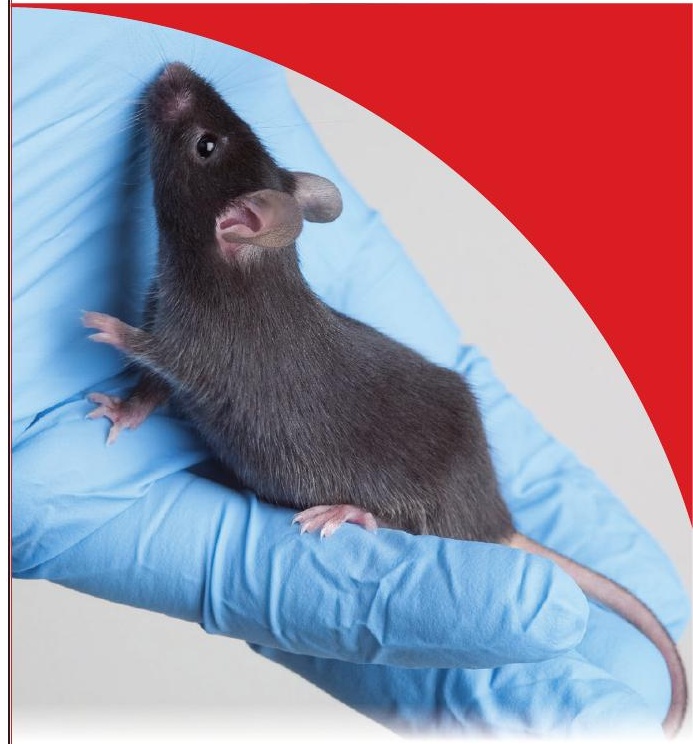

\section{Premium labware for research and discovery}

\section{Lab Animal Science}

- Blood collection solutions for volumes beginning at $10 \mu \mathrm{l}$

- Specimen transport and storage

- Liquid handling and general labware

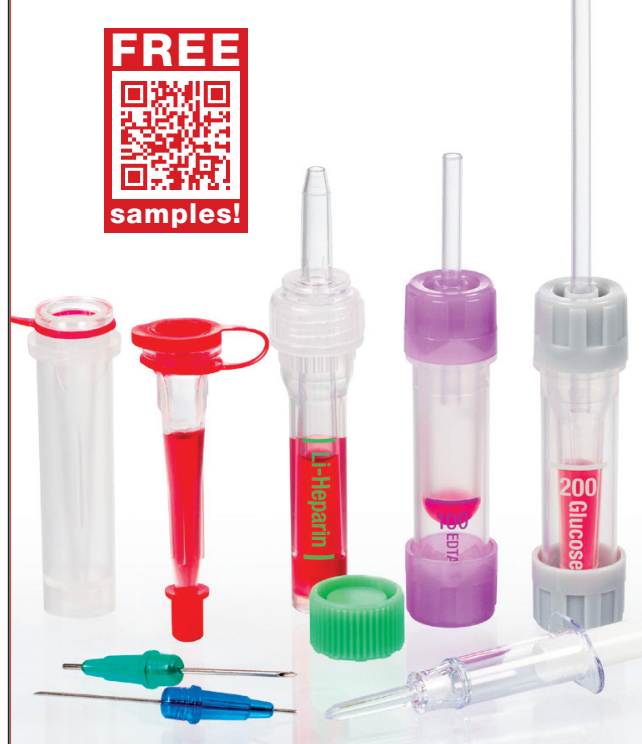

www.sarstedt.com 
Female $4(158162,129129)$

Larva 30-3 (158 162, 111 129)

Larva 30-4 (---- , 111 129)

Larva $30-6(158162,111129)$

Larva 30-9 (160 162, 111 129)

Female 6 (158 158, 111 111)

Larva 30-1 (158 160, 111 111)

Larva $30-2(158158,111111)$

Larva $30-5(158160,111111)$

Larva 30-7 (158 158, 111111$)$

Larva 30-8 (158 160, 111111$)$

Larva 30-10 (158 158, 111 111)

Female 1 (158 162, 129 160)

Larva 10-1 (152 158, 129 180)

Larva 10-2 (152 162, 129153$)$

Larva 10-3 (152 162, 129 180)

Larva 10-7 (152 158, 129153$)$

Larva 10-10 (152 158, 153 160)

Larva 15-1 (---, 129 153)

Larva 15-6 (152 158, 129153$)$

Larva 15-7 (152 158, 129 180)

Larva 15-8 (152 158, 129180$)$

Larva 15-9 (152 162, 129 153)

Larva 15-10 (152 158, 129 153)

Larva $20-2(152162,160180)$

Larva 20-4 (152 158, 153 160)

Larva 25-1 (152 158, 153 160)

Larva $25-2(152162,160180)$

Larva 25-3 (152 162, 129 153)

Larva 25-6 (152 158,153160$)$

Larva 25-7 (152 162, 153 160)

Larva 25-8 (152 162, 153 160)

Larva 25-9 (152 162, 129 180)

Larva 25-10 (152 162, 129 153)

Female 2 (158 158, 120 160)

Larva 10-4 (152 158, 153 160)

Larva 10-5 (152 158, 160 180)

Larva 10-6 ( ---- , ---- )

Larva $10-9(152158,120180)$

Larva 15-2 (152 158, 120180$)$

Larva 15-3 (152 158, 153 160)

Larva 15-4 (152 158, 120180$)$

Larva 15-5 (152 158, 120 153)

Larva 20-1 (152 158, 120 153)

Larva 20-3 (152 158, 120180 )

Larva 20-5 (152 158, 160 180)

Larva 20-6 (152 158, 120153 )

Larva 20-7 (152 158, 120153$)$

Larva 20-8 (152 158, 160180$)$

Larva 20-9 (152 158, 160180$)$

Larva $20-10(152158,160180)$

Larva 25-4 (152 158, 160180$)$

Larva 25-5 (152 158, 120 180)

Cyprinodon artifrons

- Female 5 (152 158, 153 160) - Broodstock 2, but No Offspring* 0.01

Figure 3. Parentage assignment of genotyped live sheepshead minnow larvae $(n=49)$. The ML gene tree depicts the relationship of five distinct $\mathrm{CO} /$ haplotypes of sheepshead minnows with respect to the outgroup Cyprionodon artifrons. Each potential dam, two from Broodstock 1 (Female1 and Female2) and three from Broodstock 2 (Female4, Female5 and Female6), has a unique haplotype, and their respective offspring are identified by the haplotypes they share. Female 5 produced no offspring. The acronym assigned to each larva consists of a two-digit number (i.e., 10, 15, 20, 25, 30) corresponding to incubation duration in minutes, followed by a dash (-) and a sequential number from 1-10, which identifies each individual within a given set. Brackets at the tips of the branches identify the two broodstocks and their corresponding sires (Male1 and Male2). The genotypes at the two microsatellite loci (AC4 and AC23) for parents and offspring, are given in parentheses, separated by a comma.

are primarily qualitative, and genotyping error rates were not measured.

\section{Results and discussion}

Isolation of eDNA from seawater housing live 3-5-day-old fish larvae was highly successful in terms of both genotyping
(98\% for mtDNA; 94\% and 96\% for microsatellite markers AC23 and AC4, respectively) and survival rate (92\%). The Zymo Kit was more efficient than the mod-PK protocol for capturing eDNA from the seawater where each fish larva was held (Figure 2; Supplementary Table S1). Larva holding time influenced DNA yields, although this effect was only detected with Zymo Kit isolations (Figure 1). DNA yields increased from a mean of $19.57 \mathrm{ng} / \mu \mathrm{L}$ (10 $\mathrm{min}$ ) to 30.28 $\mathrm{ng} / \mathrm{\mu L}$ (25 min). Yields were highest in the 30 min samples (mean = $37.92 \mathrm{ng} / \mathrm{\mu L}$ ), but the larvae for the 30 min trials came from a different family group and, therefore, should not be directly compared with larvae from the 10-25 min trials, as factors other than time may be responsible for the higher DNA yield. Differences in DNA yield, whether due to larva holding time, or isolation method, did not affect PCR amplification, which was perfect (100\%) for the $2 \mathrm{mtDNA}$ loci targeted (Supplementary Table S2; Supplementary Figure S1). However, DNA concentration did impact PCR product yield, with the brightest bands obtained when using Zymo Kit isolations of larvae held the longest (30 min) (Figure 2; Supplementary Figure S1). For this reason, in ensuing sequencing and microsatellite genotyping, only Zymo Kit isolations were used as template DNA. Accordingly, DNA concentration affected the quality of $\mathrm{CO}$ sequences, with larvae held $>20 \mathrm{~min}$ producing higher sequence quality scores (QV > 55) across the majority of nucleotides determined (data not shown). However, sequences of comparable quality were obtained for at least 2 larvae incubated the shortest time (10 min). Despite differences in yield, the quality of the $\mathrm{CO} /$ sequences was sufficiently high to unequivocally assign $98 \%$ of the larvae to 4 dams out of the 5 potential mothers based on matching haplotypes (Figure 3), revealing that Female 5 produced no offspring. Only 1 of the 50 larvae tested (larva 10-8) failed to generate readable sequence, perhaps due to the very low PCR yield obtained for that specimen (Figure 2A, Lane 9). Since that same specimen could only be genotyped at one locus (AC4), it was not possible to determine parentage (see Supplementary Table S1). Similar to mtDNA amplification, template concentration affected microsatellite amplification such that the strongest fluorescent signals were obtained for larvae held for $30 \mathrm{~min}$ (data not shown). Nevertheless, it was possible to genotype the majority of the larvae at both microsatellite loci (Figure 3). Only Larva 10-6 failed to amplify at both loci, but its mtDNA haplotype revealed that Female 2 was its mother (Figure 3). Of the remaining larvae, only Larva 15-1 and Larva 30-4 failed to amplify at locus $\mathrm{AC} 4$, yet in both instances their genotypes at locus AC23, in combination with their mtDNA haplotypes, allowed parental assignment. Since there were no 
unexpected haplotypes or genotypes, or evidence of polyploidy in any of the individuals characterized at the two microsatellite loci, it appears that the single rinse bath before incubation was sufficient to reduce any potential cross-contamination. In summary, combining genotypic with haplotypic information allowed the unequivocal assignment of 98\% (49/50) of the F1 larvae to a specific dam and sire pair (Figure 3).

DNA yield from a fish larva can be expected to vary depending on the size of the individual and the morphology of a given species. Since the original volume $(200 \mu \mathrm{l})$ of seawater in which each larva was held was divided into 2 equal aliquots to compare the 2 isolation protocols directly, the yields with the Zymo Kit (Figure 1) should double. Accordingly, 16 $\mu \mathrm{g}$ of DNA may be obtained from a $4-5 \mathrm{~mm}$ live sheepshead minnow larva held for 30 min using the entire volume (200 $\mu$ l) of seawater (Supplementary Table S1). Furthermore, other methods of DNA capture, such as solid-phase reversible immobilization (SPRI) (31) using commercially available magnetic beads, may produce even higher yields. Since the amount of DNA isolated correlated with incubation time, this could be increased or decreased according to specific experimental needs or to the life history requirements and fragility of the larvae. For sheepshead minnows, holding time duration appears not to affect mortality, since none of the 4 deaths came from the subsets of specimens held for 25 min or longer $(n=20)$. Instead, handling and the size of the larva appear to be more critical, given that 3 of the 4 recorded deaths ranked among the smallest specimens assayed ( 3.0 mm TL), with their deaths occurring sometime within the first $24 \mathrm{~h}$ after initial handling (Supplementary Table S2). Improvements in handling may increase survival rate when isolating DNA from live larvae. However, since there was no unmanipulated control group for this experiment, it is impossible to say whether the deaths of the smallest larvae were different from what would be expected due to natural mortality.

To date, aqueous eDNA has been primarily used for species detection (reviewed in References 32 and 33). Here, captured eDNA was used for genotyping live fish hatchlings at both mitochondrial and nuclear DNA loci with sufficient resolution to assign parentage, making the approach useful in scenarios that include communal rearing of multiple families. Using additional microsatellite markers, individual identification (i.e., genetic tagging) should be feasible, and through the characterization of potentially adaptive genes prior to testing, it may be possible to conduct evolutionary studies, including those measuring the effects of climate change using early life history (ELH) stages. The genotyping protocol described here could bypass a persistent bottleneck in generating zebrafish (Danio rerio) knockouts due to the time required to identify transmitting founder fish and subsequent carriers via traditional fin clip approaches (13). Accordingly, our protocol could be adapted to genotype the live larvae of zebrafish and other model species such as medaka (Oryzias latipes), and Atlantic silversides (Menidia menidia), with the advantage that the method conforms to protocols for the proper handling of animals, including the avoidance or minimization of discomfort, distress, and pain. This study focused on demonstrating the feasibility of a new, non-lethal DNA isolation protocol using a small sample size where the parental stock contained sufficient genetic variability to allow just three markers to unambiguously assign parentage. However, in breeding scenarios utilizing a larger number of broodstock fish at varying levels of relatedness, a greater number of markers may be required to draw meaningful conclusions about kinship.

\section{Author contributions}

J.R.A.B. conceived the idea for the study. J.M.P. captured the parental stock and was responsible for animal husbandry and DNA isolations. G.J.E. and J.M.P. performed all genotyping experiments. G.J.E. and J.R.A.B. analyzed the data. J.M.P. and G.J.E. drafted the manuscript, and J.R.A.B. wrote the final version. All authors approved the final submission of this manuscript.

\section{Acknowledgments}

Special thanks to the Texas A\&M University Sea Life Center for providing housing for the broodstock and larvae, and to the Fall 2015 Mariculture (MARB423) class for assisting with the animal husbandry aspects of this study. Thanks to Kim Clausen-Sparks for assistance with images. This project was funded in part by the Texas Institute of Oceanography (TIO), NOAA SK Award NA15NMF4270345, and the Department of Marine Biology at Texas A\&M University, Galveston Campus.

\section{Competing interests}

The authors declare no competing interests.

\section{References}

1. Ho, S.Y.W. and B. Shapiro. 2011. Skyline-plot methods for estimating demographic history from nucleotide sequences. Mol. Ecol. Resour. 11:423-434.

2. Colton, M.D., K.W.H. Kwok, J.A. Brandon, I.H. Warren, I.T. Ryde, E.M. Cooper, D.E. Hinton, D. Rittschof, and J.N. Meyer. 2014. Developmental

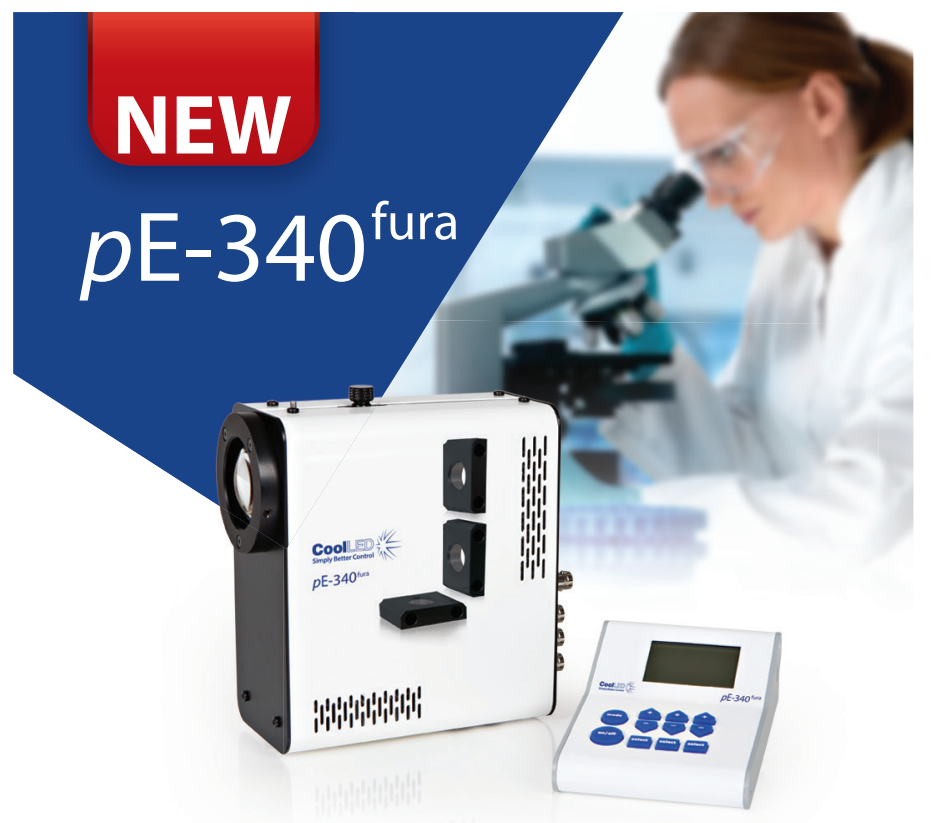

NEW Fast, Controllable LED Illumination for Fura-2 Ratiometric Calcium Imaging

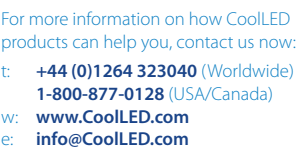


toxicity and DNA damage from exposure to parking lot runoff retention pond samples in the Japanese Medaka (Oryzias latipes). Mar. Environ. Res. 99:117-124.

3. Santos, D., M. Matos, and A.M. Coimbra. 2014. Developmental toxicity of endocrine disruptors in early life stages of zebrafish, a genetic and embryogenesis study. Neurotoxicol. Teratol. 46:18-25.

4. Foley, C.J., D.L. Bradley, and T.O. Höök. 2016. A review and assessment of the potential use of RNA:DNA ratios to assess the condition of entrained fish larvae. Ecol. Indic. 60:346-357.

5. 5. Malvezzi, A.J., C.S. Murray, K.A. Feldheim, J.D. DiBattista, D. Garant, C.J. Gobler, D.D. Chapman, and H. Baumann. 2015. A quantitative genetic approach to assess the evolutionary potential of a coastal marine fish to ocean acidification. Evol. Appl. 8:352-362.

6. Cuttitta, A., B. Patti, T. Maggio, E.M. Quinci, A.M. Pappalardo, V. Ferrito, V. De Pinto, M. Torri, et al. 2015. Larval population structure of Engraulis encrasicolus in the Strait of Sicily as revealed by morphometric and genetic analysis. Fish. Oceanogr. 24:135-149.

7. Stockwell, B.L., W.A. Larson, R.K. Waples, R.A. Abesamis, L.W. Seeb, and K.E. Carpenter. 2016. The application of genomics to inform conservation of a functionally important reef fish (Scarus niger) in the Philippines. Conserv. Genet. 17:239-249.

8. Sawayama, E., K. Asahina, and M. Takagi. 2014. Parentage assessment of incomplete ossification in larval Japanese flounder by microsatellite DNA markers. Aquaculture 420-421(Supplement 1):S98-S103.

9. Skjermo, J., I. Bakke, S.W. Dahle, and O. Vadstein. 2015. Probiotic strains introduced through live feed and rearing water have low colonizing success in developing Atlantic cod larvae. Aquaculture 438:17-23.

10. Gemberling, M., T.J. Bailey, D.R. Hyde, and K.D. Poss. 2013. The zebrafish as a model for complex tissue regeneration. Trends Genet. 29:611-620.

11. Konantz, J. and C.L. Antos. 2014. Reverse genetic morpholino approach using cardiac ventricular injection to transfect multiple difficult-to-target tissues in the zebrafish larva. J Vis Exp. www.JoVE.com.

12. Wilkinson, R.N., S. Elworthy, P.W. Ingham, and F.J. van Eeden. 2013. A method for high-throughput PCR-based genotyping of larval zebrafish tail biopsies. Biotechniques 55:314-316.

\section{Eliminate the Guesswork in CRISPR Gene Editing Detection}

\section{Confidently identify CRISPR modifications with the AccuCleave T7 kits.}

\section{Accurate detection With T7 Endonuclease I}

\section{Visualize results}

With high sensitivity detection

\section{Characterize mutations} Through zygosity identification

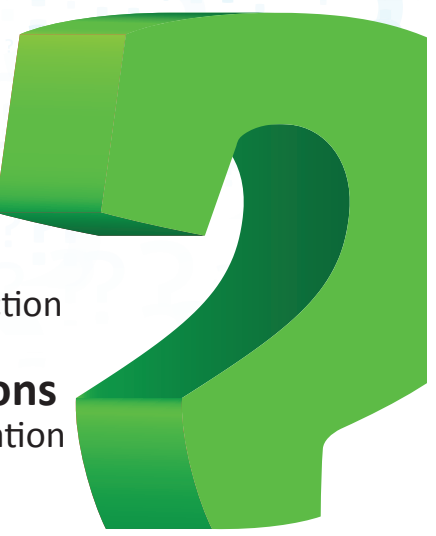

Available for both agarose gels and the Fragment Analyzer.

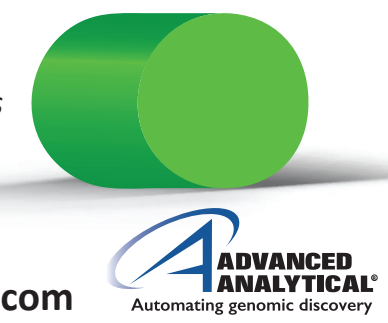

13. Luthy, S.A., R.K. Cowen, J.E. Serafy, and J.R. McDowell. 2005. Toward identification of larval sailfish (Istiophorus platypterus), white marlin (Tetrapturus albidus), and blue marlin (Makaira nigricans) in the western North Atlantic Ocean. Fish Bull. 103:588-600.

14. Alvarado Bremer, J.R., B.L. Smith, D.L. Moulton, C.P. Lu, and M. Cornic. 2014. Shake and stew: a non-destructive PCR-ready DNA isolation method from a single preserved fish larva. J. Fish Biol. 84:267-272.

15. Mirimin, L., D. O’Keeffe, A. Ruggiero, M. Bolton-Warberg, S. Vartia, and R. FitzGerald. 2011. A quick, least-invasive, inexpensive and reliable method for sampling Gadus morhua postlarvae for genetic analysis. J. Fish Biol. 79:801805.

16. de Verdal, H., M. Vandeputte, E. Pepey, M.-O. Vidal, and B. Chatain. 2014 Individual growth monitoring of European sea bass larvae by image analysis and microsatellite genotyping. Aquaculture 434:470-475

17. Cripe, G.M., B.L. Hemmer, L.R. Goodman, and J.C. Vennari. 2009. Development of a methodology for successful multigeneration life-cycle testing of the estuarine sheepshead minnow, Cyprinodon variegatus. Arch. Environ. Contam. Toxicol. 56:500-508.

18. Pirooznia, M., A. Pozhitkov, E.J. Perkins, Y. Deng, and M. Brouwer. 2010. Generation, analysis and functional annotation of expressed sequence tags from the sheepshead minnow (Cyprinodon variegatus). BMC Genomics 11:S4.

19. Nunziata, C.A. 2005. Breeding the Southern Sheepshead Minnow, Cyprinodon variegatus variegatus. American Currents 31:1-2.

20. Downing, G. and M.K. Litvak. 2002. Effects of light intensity, spectral composition and photoperiod on development and hatching of haddock (Melanogrammus aeglefinus) embryos. Aquaculture 213:265-278.

21. Ward, R.D., T.S. Zemlak, B.H. Innes, P.R. Last, and P.D.N. Hebert. 2005 DNA barcoding Australia's fish species. Philos. Trans. R. Soc. Lond. B Biol. Sci. 360:1847-1857.

22. Alvarado Bremer, J.R., A.J. Baker, and J. Mejuto. 1995. Mitochondrial DNA control region sequences indicate extensive mixing of swordfish (Xiphias gladius) populations in the Atlantic Ocean. Can. J. Fish. Aquat. Sci. 52:1720-1732.

23. Greig, T.W. 2000. Partitioning genetic variation in swordfish (Xiphias gladius L.); analysis of sample variance and population structure. Doctoral Thesis, Biological Sciences. University of South Carolina, Columbia, SC.

24. Stephens, S.H.W., C. Virginia, and J.R. Alvarado-Bremer. 2010. Assessment of genetic tissue sampling methods for critically endangered Kemp's Ridley Sea Turtle (Lepidochelys kempii). Mar. Turtle Newsl. 128:19-23.

25. Koressaar, T. and M. Remm. 2007. Enhancements and modifications of primer design program Primer3. Bioinformatics 23:1289-1291.

26. Untergasser, A., I. Cutcutache, T. Koressaar, J. Ye, B.C. Faircloth, M. Remm, and S.G. Rozen. 2012. Primer3--new capabilities and interfaces. Nucleic Acids Res. 40:e115.

27. Cruscanti, M., G. Innocenti, J. Alvarado Bremer, and B.S. Galil. 2015. First report of the brown shrimp Penaeus aztecus Ives, 1891 (Crustacea, Decapoda, Penaeidae) in the Tyrrhenian Sea. Mar. Biodivers. Rec. 8:1-4

28. Tamura, K., G. Stecher, D. Peterson, A. Filipski, and S. Kumar. 2013. MEGA6: Molecular Evolutionary Genetics Analysis version 6.0. Mol. Biol. Evol. 30:2725-2729

29. Felsenstein, J. 1981. Evolutionary trees from DNA sequences: A maximum likelihood approach. J. Mol. Evol. 17:368-376.

30. Burg, T.M., J.L. Wilcox, and A. Martin. 2002. Isolation and characterization of polymorphic microsatellite loci in pupfish (Genus Cyprinodon). Conserv. Genet. 3:197-204.

31. Hawkins, T.L., T. O'Connor-Morin, A. Roy, and C. Santillan. 1994. DNA purification and isolation using a solid-phase. Nucleic Acids Res. 22:4543-4544.

32. Goldberg, C.S., C.R. Turner, K. Deiner, K.E. Klymus, P.F. Thomsen, M.A. Murphy, S.F. Spear, A. McKee, et al. 2016. Critical considerations for the application of environmental DNA methods to detect aquatic species. Methods Ecol. Evol. 7:1299-1307.

33. Spens, J., A.R. Evans, D. Halfmaerten, S.W. Knudsen, M.E. Sengupta, S.S.T. Mak, E.E. Sigsgaard, and M. Hellström. 2016. Comparison of capture and storage methods for aqueous macrobial eDNA using an optimized extraction protocol: advantage of enclosed filter. Methods Ecol. Evol. 8:635-645.

Received 10 July 2017; accepted 06 September 2017.

Address correspondence to Jaime R. Alvarado Bremer, Texas A\&M University, Department of Marine Biology, Galveston Campus, 1001 Texas Clipper Road, Galveston, TX 77554-2888. E-mail: alvaradj@tamug.edu

To purchase reprints of this article, contact:

biotechniques@fosterprinting.com 